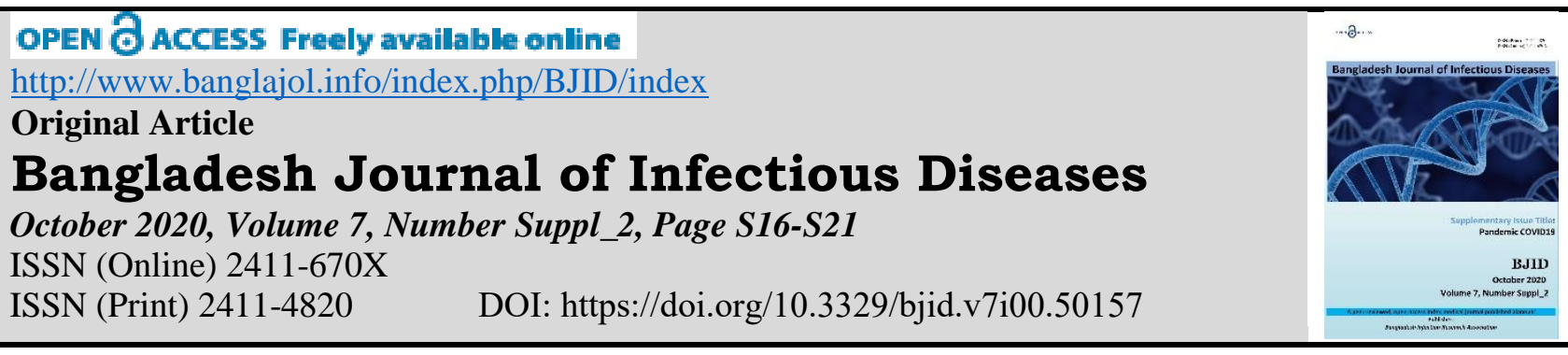

\title{
Clinico-demographic Profile of Coronavirus Infection among Bangladeshi Children: A Tertiary Care Hospital Study
}

\author{
Uzzal Kumar Ghosh ${ }^{1}$, Azmeri Sultana ${ }^{2}$, Nobo Krishna Ghosh ${ }^{3}$, Arifa Akram ${ }^{4}$, Erfan Ahmed ${ }^{5}$, \\ Imam Haidar Rana ${ }^{6}$, Ahmed Murtaza Choudhury ${ }^{7}$
}

${ }^{1}$ Registrar, Department of Paediatrics, Dr. MR Khan Shishu Hospital \& ICH, Mirpur-2, Dhaka, Bangladesh; ${ }^{2}$ Associate Professor, Department of Paediatrics, Dr. MR Khan Shishu Hospital \& ICH, Mirpur-2, Dhaka, Bangladesh; ${ }^{3}$ Professor, Department of Paediatrics, Dr. MR Khan Shishu Hospital \& ICH, Mirpur-2, Dhaka, Bangladesh; ${ }^{4}$ Assistant Professor, Department of Virology, National Institute of Laboratory Medicine \& Referral Center, Dhaka, Bangladesh; ${ }^{5}$ Assistant Director (Hospital), Dr. M R Khan Shishu Hospital \& ICH, Mirpur-2, Dhaka, Bangladesh; ${ }^{6}$ Registrar, Department of Paediatric Surgery, Dr. MR Khan Shishu Hospital \& ICH, Mirpur-2, Dhaka, Bangladesh; ${ }^{7}$ Professor, Department of Paediatrics, Dr. MR Khan Shishu Hospital \& ICH, Mirpur-2, Dhaka, Bangladesh

[Received: 17 August 2020; Accepted: 28 September 2020]

\begin{abstract}
Background: Variation and atypical presentation of COVID-19 in Bangladeshi children has been noticed. Objective: The purpose of the present study was to see the clinical and demographic features for easy and early identification of coronavirus infection. Methodology: This descriptive cross-sectional study was done at Dr. MR Khan Shishu Hospital \& ICH, Dhaka, Bangladesh from April 2020 to August 2020. The suspected case of coronavirus infection was advised RT-PCR and symptomatic home treatment was given. Hospitalization was done in severe cases. Then diagnosis was made by clinical symptoms plus investigations and appropriate treatment was given. Then RT-PCR was done among them in suspected cases. Other investigations were done accordingly. Results: Among the 236 cases RT-PCR positive was found $71(30.08 \%)$ cases. The male-female ratio was $1.7: 1$. Mostly was 1 year to 2 years $(21.13 \%)$ and 5 years to 10 years $(21.13 \%)$. About twenty percent was asymptomatic, $80.28 \%$ was symptomatic, coinfections was $29.58 \%$, and co-morbidities was $8.45 \%$. The duration of RT-PCR was positive up to two, four, six, and more than six weeks $49.30 \%, 30.99 \%, 16.90 \%$, and $2.82 \%$ respectively. Fever $(80.28 \%)$, cough $(45.07 \%)$, sore throat $(33.80 \%)$, runny nose $(29.58 \%)$, anorexia $(28.17 \%)$, convulsion $(25.35 \%)$, respiratory distress \& acute diarrhea $(15.50 \%)$, weakness $(14.08 \%)$, paralytic ileus, rash and acute abdomen (4.23\%). Conclusion: COVID-19 in Bangladeshi children are found with a variety of clinical presentations; unlike that of the adult. [Bangladesh Journal of Infectious Diseases, October 2020;7(suppl_2):S16-S21]

Keywords: Clinical; demographic profile; COVID-19; children; Bangladesh

Correspondence: Dr. Uzzal Kumar Ghosh, Registrar, Dept. of Paediatrics, Dr. M R Khan Shishu Hospital \& ICH, Mirpur-2, Dhaka, Bangladesh; Email: uzzalghosh1987@gmail.com; Mobile: +8801790117535

Conflict of interest: The author has no conflicts of interest to declare.

Funding agency: The author did not receive any type of funding for this study.

Contribution to authors: Ghosh UK, Sultana A, Ghosh NK, involved in protocol preparation, data collection and literature search up to manuscript writing; Akram A, Ahmed E, Rana IH, Choudhury AM revised this manuscript.

How to cite this article: Ghosh UK, Sultana A, Ghosh NK, Akram A, Ahmed E, Rana IH, Choudhury AM. Clinico-demographic Profile of Coronavirus Infection among Bangladeshi Children: A Tertiary Care Hospital Study. Bangladesh J Infect Dis 2020;7(suppl_2):S16-S21

Copyright: ${ }^{-2020}$. Ghosh et al. Published by Bangladesh Journal of Infectious Diseases. This article is published under the Creative Commons CC BY-NC License (https://creativecommons.org/licenses/by-nc/4.0/). This license permits use, distribution and reproduction in any medium, provided the original work is properly cited, and is not used for commercial purposes.
\end{abstract}




\section{Introduction}

Coronaviruses (CoVs) are enveloped, singlestranded, zoonotic, RNA viruses of a large family. The novel CoVs severe acute respiratory syndrome coronavirus (SARS-CoV) emerged in 2002. The 2019 novel coronavirus (SARS-CoV-2) is currently causing a severe outbreak of disease (called COVID19) in China and multiple other countries including Bangladesh. Now it is a pandemic and global health concern. In humans, CoVs mostly cause respiratory and gastrointestinal symptoms. Clinical manifestations range from a common cold to severe diseases such as bronchiolitis, pneumonia, ARDS, inflammatory syndrome, multi-organ failure, and even death. SARS-CoV and SARS-CoV-2 less commonly affect children and less severe disease compared with adults and are associated with lower fatality. Evidence suggests children are as likely as adults to become infected with SARS-CoV-2 but are less likely to be symptomatic. The majority of children infected by novel CoVs have documented household contact. In contrast, adults more often have nosocomial exposure ${ }^{1}$.

According to the National Guidelines on Clinical Management of Coronavirus Disease 2019 (COVID19) in Bangladesh shows corona symptoms are Mild illness (Influenza-like illness-ILI), Pneumonia, Severe pneumonia, Acute respiratory distress syndrome, Sepsis, Septic shock ${ }^{2}$. Common symptoms of COVID-19 in children are cough and fever. It is important to note that these symptoms may not always be present; thus, a high index of suspicion for SARS-CoV-2 infection is required in children ${ }^{3}$. Most cases in children are mild, and treatment consists of supportive care. No drugs or biologics have been approved by the USA Food and Drug Administration (FDA) for the prevention or treatment of COVID-19, and no vaccine is currently available ${ }^{4}$.

UK study says the majority of patients under 18 years old experienced a mild disease and less than $1 \%$ of them died ${ }^{5}$. A study of European children with COVID-19 suggests deaths are extremely rare. Four of the 582 children studied died, two of whom had known underlying health conditions. Children's symptoms were generally mild. Some who tested positive had no symptoms ${ }^{6}$.

Clinical manifestations of children with COVID-19 differ widely from adult cases. Fever and respiratory symptoms should not be considered a hallmark of COVID-19 in children ${ }^{7}$. So this study was conducted to see the clinical and demographic features for easy and early identification of coronavirus infection to minimize morbidity, mortality \& community transmission.

\section{Methodology}

This descriptive cross-sectional study was done at Dr. M R Khan Shishu Hospital \& ICH, Mirpur-2, Dhaka, Bangladesh from April 2020 to August 2020. Patients were attending the outpatient department and inpatients department were taken for this study. Patients without symptoms with a definitive history of contact with COVID-19 patients, with COVID-19 symptoms, with symptoms that could not be correlated with other illnesses, were included in this study. The suspected case of coronavirus infection was advised RT-PCR for COVID-19 and symptomatic treatment was given in the outpatient department. Hospitalization was done in severe cases. After hospitalization diagnosis was made by clinical symptoms criteria plus investigations accordingly and appropriate treatment was given. During the following of these cases; our suspicion arouses that they are might be COVID-19 cases or associated with other infections. Then nasopharyngeal and oropharyngeal swab was taken and sent for RT-PCR for COVID-19. Other investigations are done accordingly. RT-PCR positive cases were our sample size $(\mathrm{N})$. Data were collected with a preform datasheet by details history, demographic profile, and clinical features.

\section{Results}

Among the suspected tested samples of 236 children RT-PCR positive for COVID-19 was found in 71(30.1\%) (Table 1).

Table 1: Distribution of RT-PCR Positive Cases for COVID-19.

\begin{tabular}{|l|c|c|}
\hline $\begin{array}{l}\text { RT-PCR for } \\
\text { COVID-19 }\end{array}$ & Frequency & Percent \\
\hline Positive & 71 & 30.1 \\
\hline Negative & 165 & 69.9 \\
\hline Total & $\mathbf{2 3 6}$ & $\mathbf{1 0 0 . 0}$ \\
\hline
\end{tabular}

Among the 71 cases neonate $1(1.40 \%)$, more than 28 days to less than 3 months $2(2.81 \%)$, more than or equal to 3 months to less than 6 months $6(8.45 \%)$, more than or equal to 6 months to less than 1 year $13(18.31 \%)$, more than or equal to 1 year to less than 2 years $15(21.13 \%)$, more than or equal to 2 years to less than 5 years $10(14.08 \%)$, more than or equal to 5 years to less than 10 years $15(21.13 \%)$, more than or equal to 10 years to less than or equal to 18 years $9(12.68 \%)$ were found (Table 2$)$. 
Table 2: Age Distribution of Study Population $(\mathbf{n}=71)$

\begin{tabular}{|l|c|c|}
\hline Age Group & Frequency & Percent \\
\hline Neonates & 1 & 1.40 \\
\hline$>28$ days to $<3$ months & 2 & 2.81 \\
\hline $\begin{array}{l}\geq 3 \text { months to }<6 \\
\text { months }\end{array}$ & 6 & 8.45 \\
\hline$\geq 6$ months to $<1$ year & 13 & 18.31 \\
\hline$\geq 1$ year to $<2$ years & 15 & 21.13 \\
\hline$\geq 2$ years to $<5$ years & 10 & 14.08 \\
\hline$\geq 5$ years to $<10$ years & 15 & 21.13 \\
\hline$\geq 10$ years to $\leq 18$ years & 9 & 12.68 \\
\hline Total & $\mathbf{7 1}$ & $\mathbf{1 0 0 . 0}$ \\
\hline
\end{tabular}

Among the 71 cases Male was 43(60.56\%) and female was $28(39.43 \%)$. The male-female ratio was 1.7:1 (Table 3).

Table 3: Gender Distribution of the Study Population $(\mathbf{n}=71)$

\begin{tabular}{|l|c|c|}
\hline Gender & Frequency & Percent \\
\hline Male & 43 & 60.56 \\
\hline Female & 28 & 39.43 \\
\hline Total & $\mathbf{7 1}$ & $\mathbf{1 0 0 . 0}$ \\
\hline
\end{tabular}

Positive cases were found mostly within the Dhaka city 56 (78.87\%) (Figure I).

\section{Demography}

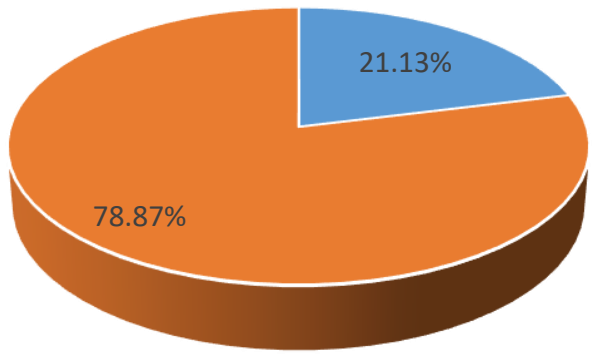

- Outside the Dhaka City $\quad$ Within Dhaka City

Figure I: showing the categorization of COVID19 Patients according to the Living zone $(n=71)$
Among 71 cases, 14 (19.72\%) were asymptomatic; symptomatic $57 \quad(80.28 \%)$, co-infections 21 (29.58\%), Co-morbidities 6(8.45\%). Documented home exposed to COVID-19 patient 39(54.93\%), IPD treatment received 35(49.30\%), OPD treatment received 34(47.89\%), ICU Care/ Referred needed 02 $(02.80 \%)$, Survived $70(98.59 \%)$, dead $1(1.4 \%)$. Duration of RT-PCR positive $\leq 14$ days $35(49.30 \%)$, $>14$ days to $\leq 28$ days $22(30.99 \%),>28$ days to $\leq$ 45 days $12(16.90 \%),>45$ days $2(2.82 \%)$ were found (Table 4).

Table 4: Categorization of COVID-19 Patients according to the following Variables $(n=71)$

\begin{tabular}{|l|c|c|}
\hline Variables & $\begin{array}{l}\text { Frequenc } \\
\text { y }\end{array}$ & Percent \\
\hline Type of Presentation \\
\hline Asymptomatic & 14 & 19.72 \\
\hline Symptomatic & 57 & 80.28 \\
\hline Co-infections & 21 & 29.58 \\
\hline Co-morbidities & 6 & $8.45 \%$ \\
\hline History of exposure & 54.93 \\
\hline $\begin{array}{l}\text { Documented home } \\
\text { exposed to COVID-19 } \\
\text { patient }\end{array}$ & 39 & \\
\hline $\begin{array}{l}\text { No home exposed to } \\
\text { COVID-19 patient }\end{array}$ & 45 & 45.07 \\
\hline Needful treatment & 35 & 49.30 \\
\hline IPD treatment & 34 & 47.89 \\
\hline OPD Treatment & 02 & 02.80 \\
\hline ICU Care/ Referred & 70 & 98.59 \\
\hline Outcome & 1.4 \\
\hline Survived \\
\hline Dead \\
\hline Duration of RT-PCR positive \\
\hline$\leq 14$ days & 35 & 49.30 \\
\hline$>14$ days to $\leq 28$ days & 22 & 30.99 \\
\hline$>28$ days to $\leq 45$ days & 12 & 16.90 \\
\hline$>$ 45 days & 2.82 \\
\hline
\end{tabular}

Fever $57(80.28 \%)$, cough $32(45.07 \%)$, sore throat $24(33.80 \%)$, runny nose $21(29.58 \%)$, anorexia $20(28.17 \%)$, convulsion $18(25.35 \%)$, respiratory distress 11(15.50\%), acute diarrhea 11(15.50\%), weakness 10(14.08\%), Paralytic ileus 3(4.23\%), rash $3(4.23 \%)$, acute abdomen 3(4.23\%), bloody diarrhea $2(2.82 \%)$, anosmia $2(2.82 \%)$, jaundice $1(1.41 \%)$, conjunctivitis $1(1.41 \%)$, arthritis1(1.41\%), unconsciousness $1(1.41 \%)$ were found (Figure II). 


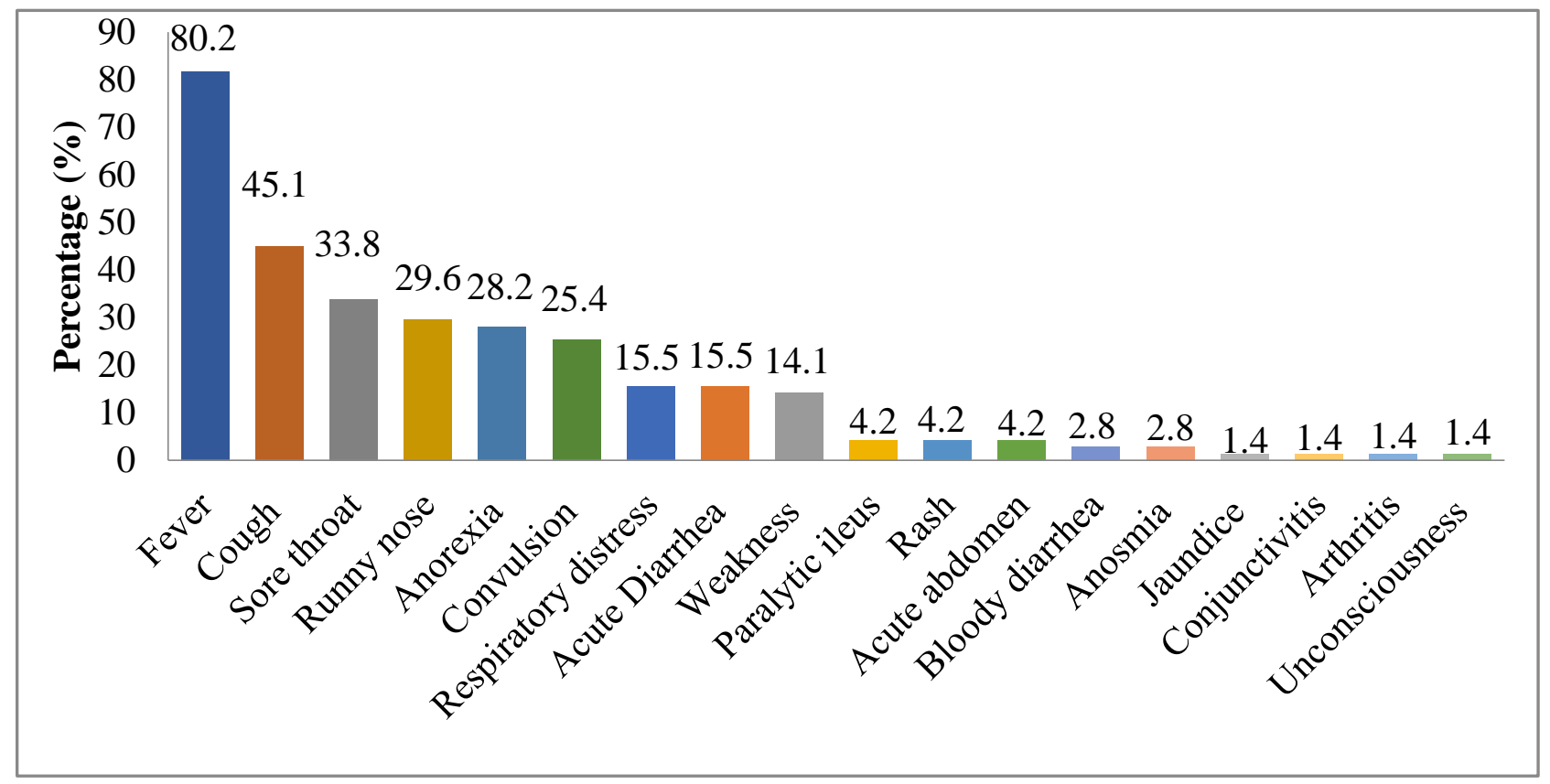

Figure II: Showing different Clinical Features among the Study Population $(n=71)$

\section{Discussion}

RT-PCR positive for COVID-19 was found 71(30.08\%) among the suspected tested sample 236. Among the 71 cases neonate one case, 28 days to less than 3 months $2.81 \%, 3$ months to less than 6 months $8.45 \%, 6$ months to less than 1 year $18.31 \%, 1$ year to less than 2 years $21.13 \%, 2$ years to less than 5 years $14.08 \%$, 5 years to less than 10 years $21.13 \%$, 10 years to less than 18 years $12.68 \%$ cases were found. China and the United States reported only about $2.4 \%$ coronavirus infection among children where age was under 19 years ${ }^{\mathbf{8}, 9}$. Male was $43(60.56 \%)$ and female was $28(39.43 \%)$. The malefemale ratio was $1.7: 1$. Positive cases were found mostly within the Dhaka city about $80 \%$.

Among the positive cases $19.72 \%$ asymptomatic, symptomatic $80.28 \%$ were found. Although reported, the child mostly remains asymptomatic but our study showed symptomatic more as the study was done in a tertiary care hospital. Reports showed COVID-19 in children is gradually increasing. The illnesses were mild $(31.3 \%)$ or ordinary $(68.8 \%)$, presenting as asymptomatic $(50 \%)^{\mathbf{1 0}}$.

Another report showed mild clinical signs and symptoms were mild (21.4\%) and conventional cases (78.6\%). ${ }^{11}$ Fifteen percent were asymptomatic, $36.3 \%$ were mild, $46.0 \%$ were moderate, $2.1 \%$ were severe, and $1.2 \%$ were found critical in another study ${ }^{7}$.

In this study, among the clinical presentation predominant feature fever $80.28 \%$, cough $45.07 \%$, sore throat $33.80 \%$, runny nose $29.58 \%$, anorexia $28.17 \%$, convulsion $25.35 \%$, respiratory distress $15.50 \%$, acute diarrhea $15.50 \%$, weakness $14.08 \%$, paralytic ileus $4.23 \%$, rash $4.23 \%$, acute abdomen $4.23 \%$, bloody diarrhea $2.82 \%$, anosmia $2.82 \%$ Jaundice $1.41 \%$, Conjunctivitis $1.41 \%$, arthritis Here, have to mention that there were overlapping of clinical features. In many studies findings like these, fever and cough were the most common symptoms. Afebrile at the onset of the disease nearly half of patients $^{\mathbf{1 2}}$. Fever and/or cough $(50 \%)$ were presenting as illness ${ }^{\mathbf{1 0}}$. Clinical manifestations in children were fever (35.7\%) and dry cough $(21.4 \%)^{11}$.

Asymptomatic, Acute upper respiratory tract infection, Mild pneumonia, Severe pneumonia Critical cases were found. Clinical symptoms of Fever, Cough, Rhinorrhea/sneezing, Sore throat, Headache/dizziness, Diarrhea, and Dyspnea/tachypnea were noticed in another study ${ }^{\mathbf{1 3}}$. Among the convulsion cases, one case was found as a status epilepticus. Four boys out of five showed neurological symptoms axial hypotonia or drowsiness and moaning sounds, or both. Lumbar punctures were done and the cerebrospinal fluid study was normal ${ }^{14}$.

One case was found conjunctivitis associated with some other features as like as Kawasaki disease in our study. Maximum cases in children were asymptomatic, mild, or moderate but having unusual presentations of a Kawasaki disease (KD)-like inflammatory syndrome associated with COVID$19^{15}$. Surgical cases were found acute abdomen were 
3 in number where one found as acute appendicitis and two found as a nonspecific abdominal pain.

A case reported at Dhaka Shishu (Children) Hospital that atypical presentation of COVID-19 as acute abdomen ${ }^{16}$. An 11-year-old boy presented with fever, diarrhea, and a maculopapular rash over both feet and severe abdominal pain with COVID-19 positive without any respiratory symptoms were seen in another case report ${ }^{17}$. A study showed that in three of the five patients, the primary onset disease required an emergency operation included intussusception, acute supportive appendicitis, perforation with local peritonitis, and traumatic subdural hemorrhage with convulsion, two cases were acute gastroenteritis (including one patient with hydronephrosis and a stone in his left kidney $)^{18}$.

Typical and main presentations of COVID-19 in adult was fever, cough, respiratory distress, and hypoxia, but the atypical presentation in children is a diagnostic challenge. Three children whose initial presentation was gastrointestinal in whom Covid-19 infection was found, concluding that cases of acute appendicitis, mesenteric adenitis, and flank tenderness ${ }^{19}$. All patients presented with a combination of symptoms including fever, abdominal pain, diarrhea, and vomiting. The working diagnosis was of systemic sepsis based on raised blood inflammatory markers thought to be secondary to suspected appendicitis ${ }^{20}$.

All the surgical cases were managed by conservatives in our study. A study has been revealed a milder course of COVID 19 in children with minimal infectivity even when present in association with emergency surgical conditions. This might encourage a gradual restart to mitigate the impact of COVID 19 on children's surgery ${ }^{21}$.

Among positive cases, co-infections were found about one third percentage cases in this study. So, coinfection is not very uncommon with COVID-19. Enteric fever, typhus fever, bacterial meningitis, bacterial pneumonia, UTI, hepatitis A, E virus infection, etc. found as co-infections among Bangladeshi children in our study. Many studies showed co-infection with COVID-1922-27. Although co-infection pattern depends upon an epidemiological and geographical location.

Co-morbidities were found in about $10 \%$ cases where one case was juvenile diabetes mellitus, two cases were bronchial asthma and three cases were congenital heart disease. Nearly Forty patients (83\%) had significant preexisting co-morbidities published in another study ${ }^{28}$. A case reported co-infection with comorbidities, a 4-month-old boy with a muscular ventricular septal defect, and atopic dermatitis presented with gastroenteritis and respiratory tract infection with a documented history of home exposure to COVID-19. The initial respiratory pathogen was positive for adenovirus. But on the following day, the COVID-19 PCR was also positive ${ }^{29}$.

Documented home exposed to COVID-19 patient $54.93 \%$. Without documented home exposer nosocomial infection might be a great concern. A study found where all cases were of family clusters ${ }^{\mathbf{1 1}}$. IPD treatment received 35 cases, OPD treatment received 34 cases, ICU Care/ referred only 2 cases where 70 cases survived and dead one case. In a study, about one in 10 needed intensive care ${ }^{6}$. Less than $1 \%$ died among the children found in a UK study ${ }^{5}$. Duration of RT-PCR positive up to14 days $49.30 \%$, up to 28 days $30.99 \%$, up to 45 days $16.90 \%$, more than 45 days $2.82 \%$ were found.

There are some limitation of this study. It is a singlecenter tertiary level hospital study. A communitybased study is needed for a more conclusive result.

\section{Conclusion}

In conclusion, COVID-19 in Bangladeshi children are found with a variety of clinical presentations; unlike that of adults. Asymptomatic to the symptomatic presentation is found where clinical features like fever, cough, sore throat, runny nose, anorexia, convulsion, respiratory distress, acute diarrhea, weakness, paralytic ileus, rash, acute abdomen, bloody diarrhea \& anosmia, jaundice, conjunctivitis, arthritis and unconsciousness, and positive cases are found mostly within the Dhaka city.

\section{References}

1. Zimmermann, Petra, Curtis, Nigel. Coronavirus Infections in Children Including COVID-19. The Pediatric Infectious Disease Journal, May 2020; 39(5): 355-68.

2. National Guidelines on Clinical Management of Coronavirus Disease 2019 (COVID-19); Version 4.0 30 March 2020: Disease Control Division, Directorate General of Health Services, Ministry of Health \& Family Welfare, Government of the People's Republic of Bangladesh. Pp 9-10.

3. Issa B, Cennimo DJ. Coronavirus Disease 2019 (COVID-19) in Children. Medscape. Drugs \& Diseases > Pediatrics: General Medicine; updated Jul 23, 2020.

4. NIH Clinical Trial Shows Remdesivir Accelerates Recovery from advanced COVID-19. National Institute of Allergy and Infectious Diseases (NIAID) 29 April 2020.

5. Dr. Ayodola Adigun. COVID-19 disease in children is usually mild, fatalities rare, Abc News Coronavirus Health \& Science 26 June 2020. 
6. Coronavirus: Most children 'experience only mild disease'. Health: BBC News 26 June 2020.

7. De Souza TH, Nadal JA, Nogueira RJN, Pereira RM, Brandão MB. Clinical manifestations of children with COVID19: A systematic review. 03 June 2020.

8. WHO. Report of the WHO-China Joint Mission on Coronavirus Disease 2019 (COVID-19). World Health Organization. 2020 Feb 28; Accessed: 9 April 2020.

9. CDC COVID-19 Response Team. Coronavirus Disease in Children- United States, February 12-April 2, 2020; 69 (14):4226.

10. Song W, Li J, Zou N, Guan W, Pan J, Xua W. Clinical features of pediatric patients with coronavirus disease (COVID19). J Clin Virol. 2020 Jun; 127: 104377.

11. Du W, Yu J, Wang H, Zhang X, Zhang S, Li Q, Zhang Z. Clinical characteristics of COVID-19 in children compared with adults in Shandong Province, China 2020 Apr 16: 1-8.

12. Bal, Zümrüt Şahbudak; Kurugöl, Zafer; Özkınay, Ferda. Clinical features of COVID-19 in children. J. Pediat. Res.; 2(7): 88-91, 20200601

13. Choi SH, Kim HW, Kang JM, Kim DH, Cho EY. Epidemiology and clinical features of coronavirus disease 2019 in children. CEP 2020; 63 (4):125-32.

14. Atypical presentation of COVID-19 in young infants. April 272020 https://doi.org/10.1016/S0140-6736 (20)30980-6. www.thelancet.com May 9, 2020; vol 395.

15. Behera B. Presentation of COVID-19 as Atypical Kawasaki Disease in Children. International Journal of Research and Review June 2020; 7 (6): Website: www.ijrrjournal.

16. Samiul Hasan, Ayub Ali, and Umme Huq. Acute Abdomen as a Presentation of COVID 19 in Children: Our Early Experience. RPN.000596.2020.

17. Periyakaruppan M, Kumar S, Kandasamy S, Thiagarajan A, Sangaralingam T, Ganapathy N. COVID Abdomen: SARSCoV-2 Infection presenting as 'Acute Abdomen' in a Child. 23 Jun 2020. Case Report Pediatrics, Critical Care \& Emergency. 18. Cai X, Ma Y, Li S, Chen Y, Rong Z, Wenbin. Clinical Characteristics of 5 COVID-19 Cases With Non-respiratory Symptoms as the First Manifestation in Children. Front. Pediatr. 12 May 2020
19. Ekbatani MS, Hassani SA, Tahernia L, Yaghmaei B, Mahmoudi S, Navaeian A, Rostamyan M, Zamani F, Mamishi S. Atypical and novel presentations of Coronavirus Disease 2019: a case series of three children, British Journal of Biomedical Science.

20. Tullie L, Ford K, Bisharat M, Watson T, Thakkar H, Mullassery D et al. Gastrointestinal features in children with COVID-19: an observation of varied presentation in eight children.19 May 2020; 4 (7):e19-e20.

21. Hasan MS, Ali MA, Huq U. Outcome of COVID-19 with coexisting surgical emergencies in children: our initial experiences and recommendations.

22. Wu Q, Xing Y, Shi L, Li W, Gao Y, Pan S, Wang Y, Wang W, Xing Q. Co-infection and Other Clinical Characteristics of COVID-19 in Children. Pediatrics 2020;146(1):e20200961.

23. Haqqi A, Khurram M, Salah Ud Din M, Aftab MN, Ali M, Ahmed H, Afzal MS. COVID-19, and Salmonella Typhi coepidemics in Pakistan: A real problem 10 Jul 2020.

24. Verduyn M, Allou N, Gazaille V, Andre M, Desroche T, Jaffar M-C, et al. (2020) Co-infection of dengue and COVID-19: A case report. PLoS Negl Trop Dis 14(8): e0008476.

25. Akram A, Jewel MSH, Chowdhury R, Chowdhury MRU. A case report of nosocomial infection with SARS CoV-2 in a oneyear-old Meningoencephalitis patient in a tertiary hospital of Bangladesh. Microbes and Infectious Diseases, 2020.

26. Wander P, Epstein M, Bernstein D. COVID-19 Presenting as Acute Hepatitis. The American Journal of Gastroenterology 1 April 2020; 115(6)

27. Mandelia Y, Procop GW, Richter SS, Worley S, Liu W, Esper F. Dynamics and predisposition of respiratory viral coinfections in children and adults [published online June 12, 2020]. Clin Microbiol Infect.

28. Shekerdemian LS, Mahmood NR, Wolfe KK, Riggs BJ, Ross CE, Christine AC et al. Characteristics and Outcomes of Children with Coronavirus Disease 2019 (COVID-19) Infection Admitted to US and Canadian Pediatric Intensive Care Units. JAMA Pediatr. May 11, 2020.

29. Danley K, Kent P. 4-month-old boy coinfected with COVID19 and adenovirus. Unusual association of diseases/symptoms Case report 2020; 13(6). 